\title{
XXXV. On the buds and ramifications of plants; the birth of these organs, and the organic relation between the trunk and the branches
}

\section{G.L. Koeler M.D. \& M. Ventenat}

To cite this article: G.L. Koeler M.D. \& M. Ventenat (1805) XXXV. On the buds and ramifications of plants; the birth of these organs, and the organic relation between the trunk and the branches, Philosophical Magazine Series 1, 22:87, 231-241, DOI: 10.1080/14786440508562448

To link to this article: http://dx.doi.org/10.1080/14786440508562448

曲 Published online: 18 May 2009.

Submit your article to this journal $[\pi$

Џll Article views: 2

Q View related articles $\sqsubset$ 
class. We shall add, that a series of experiments made with an apparatus of larger dimensions, and executed with more care than that employed by the commissioners, might furnish results useful to artillery.

XXXV. On the Buds and Ramifications of Plants; the Birth of these Organs, and the organic Relation between the Trunk and the Branches: in a Letter from G. L. KozLer, M.D. Professor of Botany and the Materia Medica in the Provisional School of Medicine at Mentz, to M. Ventenat, Momber of the French National Institute*

\section{TY DEAR FRIEND,}

Nature seems to have thrown an impenetrable veil over the development of vegetable parts. In vain have botanists made efforts to surprise her; in vain do they watch her; she eludes their efforts, and laughs at their indefatigable patience. If it has been impossible, however, to accomplish by observations this end, which was the object of so much care and labour, their researches have still conducted them to a multitude of other valuable discoveries, which have assisted us in the study of the structure and interior ceconomy of plants, and have shown to us the causes of several phænomena before considered as inexplicable.

The opinions of those who have endeavoured to discover in what manner nature develops one vegetable organ from another may be ranged into two classes.

Some have imagined that it is the pith, which makes its way through even the hardest wood to produce the ramifications of plants, and that it lengthens itself still to form the most essential parts of the vegetable body.

Others, and those the most recent, rejecting this opinion, have ascribed to the bark and cortical strata what their predecessors gave as the product of the pith. They have thought also that the increase in length and thickness depends on the same organs.

Placed between these two opinions, and though each of them was supported by great names, yet being unwilling jurare in verla magistri, I resolved to examine both without prejudice, and to give an opinion supported by my, own observations. I did so; and discovered that Linnæus and Hales, who had maintained the former opinion, were

* From the Journal de Physique, Floreal, an 13. 
not far from the truth; that their error was very excusable. for they might easily take for pith the reproducing organ, which will be mentioned in the course of this letter, and the herbaceous substance of which has a resemblance to that of this spongy organ. It may be said further in their favour, that they had not before them the experiments of Desfontaines, Coulomb, Hedwig, Mirbel; and Medicus, and so many other philosophers who have thrown light on a great number of points hitherto inexplicable in regard to the interior aconomy of vegetables.

The observations which this study gave me an opportunity of making, have conducted me to results so unexpected, that I did not think proper at first to trust to my own eyes. Convinced without being persuaded, and distrusting my own senses, especially in an experiment the results of which were in open contradiction to what we are taught by the greatest masters, I resolved to submit to you these observations, and to give them at the same time publicity, in order to call the attention of the most enlightened botanists to the new phanomenon which I think I have perceived. I must, however, say, that it is the force of conviction, the desire of instruction, and not a vain spirit of controversy so unworthy of a real naturalist, which induce me to think differently from several celebrated men superior to envy, and to whom I readily pay the tribute of my gratitude for the benefit $I$ have received from their works.

Before I give my observations on the origin of buds, I shall first rectify some ideas generally adopted in regard to these organs.

"The name of lud is given in botany to small bodies more or less round or ovoid, and covered with scales hollowed out like a spoon, or with a down more or less thick. These organs are formed gradually in the spring season in the eyes of the leaves of most 1rees, shrubs, and plants of the dicotyledons, especially in climates where the winters are pretty severe. They contain and conceal the rudiments destined to be developed the following year into branches, Jeaves, and flowers. They have received from nature the faculty of resisting cold and humidity: several of them may be preserved, like a great many seeds, during one or more years, by remaining in a state of torpor until the development of their parts is excited by favourable circumstances."

These are the principles commonly received in regard to buds in general; but it appears to me that they are suited properly but to one species, that of most trees and shrubs in counirics where the winter is pretty severe.

I shall 
I shall now explain what, in my opinion, ought to be comprehended under the denomination of the buds of phamegoram plants. I give this name to all the organs of these plants which contain the rudiments or germs of stems, branches, leaves, flowers, and even roots: each of these parts separately, or several of them united; or, in a word, the whole together. This name belongs to them whatever be their size; their number; that of the different parts of which they are composed; the time of their appearance; their property of being preserved ; the species which produces them, and the place of their insertion: modifications and peculiarities which depend on the different structure of the plants as well as the circumstances under which they are placed.

The definition I have given seens to me to unite several advantages: it embraces not only the whole of the organs together, even in regard to their origin; it dispenses also with the inconvenience of admitting a great number of exceptions in the uniform progress of nature; exceptions which no doubt prove that they have not been safficiently examined. It is pretended that shrubs are distinguistied from bushes or trees by their ramifications not being the result of buds. This distinction is merely arbitrary, simae these plants really produce them; but their buds are very small, exceedingly thin, destitute of dry scales, and sometimes almost entirely concealed till the spring under the bark of the branches.

Admitting the definition I have proposed, it will be observed that buds differ from each other by a great number of characters in the various species of plants. I shall here mention only those traits which are indispensably necessary to support my definition.

In the ligneous monocotyledon plants the whole course of life is confined to the development of the first bud, arising from the neck of the root or place where it is joined to the stem. This bud contains the germs of all the organs which appear above the earth, and the end of its development is the rerm also of the life of the same plant. These plants, however, generally live one, and even several, centuries.

The propagation of plants by scions, by bulbs, and by other similar organs, which is very common to the herbaceous monocotyledons, is not essentially differen $t$ from that by buds, as has been completely proved by M. Mirbel and several other botanists. Scions and bulbs are real buds; they are organs which contain the principles of new stems, branohes; leaves, flowers, and roots. The part of the plant 
which produced them, and some modifications in their structure, make them, however, be considered as species different from every other.

In the dicotyledon plants and the herlaceous monocotyledons the summit of the root bears during the early age of the plant a single bud, named then plumula. This bud differs from that of the monocotyledon trees, as its development is ended before the death of the individual, and is followed by other buds, in consequence of the development of which the plant ramifies. The monocotyledon trees produce also secondary buds, but with this difference, that these buds are pushed out by the primitive bud itself, and that they fade much sooner than that from which they proceeded.

In annual plants the development of all the buds of the individual is completed in the space of a year. In the $b i$ ennial plants it is terminated at the end of two years at most. Plants with a vivacious root but annual stem push out every year another bud from the neck of the root: from the developed parts of this principal bud other buds then issue, which make the ramifications of the vegetable appear.

The buds of the three sorts of plants here mentioned are not all, or very rarely are, covered with other argans to protect the germs against the intemperance of the weather. Here nature, in general, may dispense with them, because these buds develop themselves in the course of a very short time, and almost always in the best seasons; and the plants, or at least the stems, to which they are indebted for their birth, perish in the winter, or even sooner.

In most of these plants, as well as in bushes and some shrubs, the buds are small, thin, and pointed, as in the viburnum, the rhamnus (buckthorn), the heliotrope, the cornel tree, the gramineous plants, the artemisia, \&c.

The ligneous dicotyledon plants in general push forth their buds only in spring. Their buds in winter remain in a state of inaction, and do not open till the return of spring. From this rule, however, are excluded all trees and bushes called evergreens, a great number of which perpetually send forth buds, so that the development of the leaves, branches, and even sometimes the flowers, never ceases during the life of these plants.

In almost all the dicotyledon trees and shrubs of the cold and temperate climates, the buds are formed in the eyes of the leaves, and always before the approach of winter. Botanists consider the most exterior folioles of these buds as alorted folioles, beoause. they are dry and even sometimes sonorous 
sonorous under the fingers. They are called scales, on account of their usual form. These organs are almost always covered with a resinous matter, which cements them very closely to each other, and which contributes not a little to defend the tender yerms contained in the buds from the cold and moisture of the severe seasons.

In a great number of bushes and shrubs these scales are entirely wanting; but their place is supplied in several species by a down, which sometimes is pretty thick, and which affords sufficient protection to the buds against the rigour of the winter, as in the vilurnum and the ptelea. In other buds of similar plants the parts still herbaceous and tender have neither down, nor scales, nor resinous matter, nor any other kind of covering, and they nevertheless with? stand the intemperance of the seasons, unless it be excessive. Among the latter there are some the folioles of which cover each otber firmly, as in the common lilac, the hazle, \&c.; and there are same also in which the exterior folioles are neither so thick nor so firmly applied to each other as to be able to oppose the entrance of humidity, as is the case in the cornel tree.

The buds of several ligneaus dicotyledon plants remain, in regard to their base and a great part of their body, concealed during winter under the bark, and their summit does not entirely open a passage for itself till the following spring. Here the bark serves as bandages to the tender elements of the new ramifications, as we see in a great number of shrubs:

Nature incloses the buds in several shrubs, as in the lerberis vulgaris, with petioles very close to each other; it coyers them also on one side by the branch from which they have proceeded, and on the other by the flat base of the prickles.

In the last place, there are some ligneou's dicotyledon vegetables the buds of which are concealed and sheltered from the pernicious influence of the weather in a manner as singular as wonderful. The buds, unprovided with scales, but covered with a fine and thick down, form themselves under the concave base of the supporters of the leaves. During winter these supporters remain in their place in several plants; but when the sap ascends, the eye, becoming larger, rejects the tutor, of which it has no longer need. Sometimes shocks, and other accidents, make them fall earlier: in this case, the bud, being still secured by its natural pelisse, escapes generally the severe cold of winter.

I have observed that the supporter in question differs according 
cording to its nature. In several plants it is a real petiole, as in the seringa, \&c.; in others it is, as it were, an intermediate organ between the branches and the petioles, because it is not hollowed out in grooves at its upper surface, but entirely round; because its substance is more ligneous than herbaceous, though it falls annually; and because it forms internally a canal containing real pith, and closed towards the base of the petiole, so that the pith does not communicate with that of the part to which this supporter is attached. Similar supporters are found in the rhus coriaria, the acer negundo, the robinia, \&re.

About three years ago I made this observation on the shumac; and I have reason to believe that no one ever made it before me, since I in vain consulted on this subject all my books on botany. I proposed to make a series of researches on this subject; and, indeed, they convinced me that mature covers in this manner the buds of several ligneons dicotyledons considered hitherto as not bearing any. It was my intention not to publish ma observations until $\mathbf{I}$ had sufficiently repeated them, which could not be done till I had examined a much greater number of vegetables. But a little while ago I found in the Mémoires pour servir a l'Anatomie et à la Physiologie Végétales, par M. Medicus*, that this celebrated botanist had made the same observation on plane-trees. I immediately had recourse to other works, such as your excellent Tableau du Regne Végétal; and, though I found nothing in the first volume under the articles relating to that subject, I found in the third + that this peculiarity of the plane-tree had not escaped you. I then consulted the Traitê des Arbres et Arbustes, by Duhamel, where, under the article Platamus, this great observer makes mention of the same phanomenon, without pointing out, however, whether it was known before; but as it has been known since that time, how comes it that no botanist, in treating specially of buds, has rectified his definition according to this observation?

Shumac furnished me also with an opportunity of observing several phænomena in regard to the birth and development of buds. I shall give you an account of them as briefly as possible.

Almost all botanists have adopted the opinion, that the leaves in the eyes of which the buds shoot forth approach, towards the end of their life, to the ligneous state by the

* Beytrage zur Panzen anatontie und Pflanzen physiologie, haft i. p. 24. . + Page 578. 
influence of the rays of the sun and of the air, and that they then no longer afford a free passage to the ascending sap. It is supposed that the fluids stop, and are accumulated at the base of these leaves, and that they thereby give birth to camlizm, which occasions the ring or swefling there observed. It is pretended also that this camlizim produces new vesscls, which, obeying the impulse they daily receive from the ascending sap, become lengthened towards the surface of the bark, and force themselves to pierce it; after which they give birth to the bud.

This explanation, though ingenious, appears to me to be only a bold hypothesis, supported by facts which have not been examined with sufficient care. Instead of beginning by an explanation, it would have been better to discover first all the facts and all the circumstances by which this phænomenon is accompanied. And still we shall succeed as little in penetrating into this operation as we have done in regard to all the rest, the secret of which nature seems to have reserved to herself: the formation of the individuals and of their organs will be always inexplicable to us. $\mathrm{Na}$ ture, however, far from precluding us from researches, excites us rather to watch her; and it is then that, by attending with assiduity and without prejudice, we often discover facts which form one step towards the truth. It may be objected to this explanation, that there are, indeed, buds which do not pierce the bark in the eyes of the leaves, and that the eye shows itself already at the time when the leaves lhave lost none of their vigour.

I shall now return to my own observations. In examining with attention the ligneous dicotyledon plants at the different seasons, it will be observed that a body almost always soft, herlaceous, and green, when it issues from the wood, enters into the bud destined to develop flowers or a branch, and that this body forms in reality the centre or axis of the bud. The same observation will ba made when the wood of the branch which throws out the bud is already formed of several annual zones. It will be perceived also that this herlaceous body is rarely aione; that it has, for the most part, on each side, and at a very smali distance from it, auother lody, and sometimes tw , but of the same sub. stance as itself: these lateral herbactrus lodies are smaller than it, and never penetrate into the substance of a bud which produces branches or flowers: they enter into those only of the leaves; that is to say, into those a petiole or leaf of which is destined to develop itself, which we observe at the base of a $t w i g$ in several shrubs and bushes. There 
is sometimes also at the base, and very near the largest herbaceous body, a similar body, which penetrates with it into the same bud. All these herbaceous lodies are produced each separately in a medullary sheath, and never in the bark, the liber, or the alburnum, nor in the annual zones of the wood. They are indeed the prolongations of the indles of tules of the medullary sheath*.

The herbaceous bodies of which I here speak, in passing into the wood are not always in a horizontal direction: $\mathbf{I}$ mean, that they do not form in all the plants which $I$ have examined a right angle with the medullary sheath: in several trees and shrubs they leave it much lower than the place where the bud issues from the bark, as is the case in the shumac, plane-tree, willows, \&c.

When the bark, with the bud, has been removed, these herlaceous prolongations present themselves under different forms, according to the species to which they belong, the age of the branch, the place even where they are, and the angle at which they have traversed the wood. This is the reason why the figure of their section in the exterior zone of the wood varies from the form of a line or stroke to that. of a point entirely round; sometimes there are several of them united, so that altogether they form scarcely a single line or oblong point. At the place where these herbaceous. bodies traverse the wood, the ligneous fibres are separated from each other; and though they press them more or less, they still leave thern a sufficient passage. This separation of the tubes and fibres of the wood is more apparent in the zones near to the medullary case, than in those which are more distant, and consequently nearer to the bark.

The thickness of these bodies differs also in the different species of plants. In those the wood of which is hard and compact they are smaller, and at the same time less cylindric than in those the wood of which is light. Those destined to push forth buds for twigs and flowers have more volume than those which produce leaf-buds.

They do not always remain green : they lose that colour as they change into wood. But they are found herbaceous, and filled with green substance, at least, until the bud has expanded into a flower-bud; and I have observed that they are still green and herbaccous, even in the twigs and young* branches, if the wood of the species from which they have proceeded be white and light.

* These vessels are porous tubes, large simple tubes, trachex, and false trachex. See Tratté d'Anatomie et de Pbysiologie v't́gétales, par Brisseau Mirbel, rol. i. p. 186, et seq.; and the same in Dict. des Sciences Naturelles, vol. ii. \$. $\$ 69$. 
The same prolongations are found in herbaceous plants with a ramified stem: for example, in the adult stems of the common cabbage, \&c., where one may be convinced that the branches have no other origin there than that of the medullary sheath, and that they issue from real buds.

It seems to result, from what I have here said, that the reproducing organ of bùds in the dicotyledon plants, is effectively and exclusively the case or sheath which contains the pith: it is even in the herbaceous monocotyledon plants, the spaces between the knots of which form empty tubes: nature, to produce branches, has formed in these plants solid knots or articulations, the structure of which is almost the same as that of the stems of plants the canal of which contains pith.

The opinion that the medullary case is the only organ which gives rise to buds, and consequently to branches, is confirmed by the observations which I made on the insertion of old branches even in trunks entirely dry. For this purpose I carefully examined the branches of the pine fir and prunus spinosa (sloe-tree), shumac, oak, apple-tree, $\& c_{\text {, }}$, and every where I observed the same result. It is true, that in the old branches the prolongations are more herbaceous, and on that account are difficult to be distinguished, because the one which has penetrated into the principal substance of the bud, from which the branch has proceeded, has become ligneous : the small lateral ones are not even dried, and are still entirely covered and concealed both by the base of the branch, and by the annual strata of the wood, which had been formed after these prolongations had thrown out petioles or leaves. The perpendicular section of a branched trunk always shows, whatever be the number of the concentric strata of the ligneous body, that the medullary sheath of the branch proceeds from the medullary sheath of the trunk; that the branch never forms in the trunk an inverted cone, the summit of which is concealed by the strata of that part; and that the branch of 2 tree can never be compared, as has been done, to a plant the roots of which are in a ligneous soil. The different annual strata of a branch never cover each other, in any case, at their respective bases ; and they are never separated from those of the trunk. These strata are in immediate communication with those of the trunk, in such a manner that the strata of the branch seem to have arisen from a prolongation of those of the trunk. It is very difficult to distinguish whether the medullary sheath takes its origin 


\section{On the Buds and Ramifications of Plants.}

from that of the trunk, when the medullary canal of that part is filled with ligneous strata, which is the case in several bushes and shrubs where an interior liber is formed annually of the pith, until the canal which contains it has altogether disappeared, as in the ash, the oak, shrmac, \&c. ; but it is principally in the latter that we mav be convinced that it is never by the medullary sheath, nor by the interior cambium, that these internal zones are produced.

The increase in length of buds and twigs is ascribed to an erection of the tubes of the liber. If the has of a young branch be separated as far as the terminal bud in a young poplar, for example, and particularly before winter, or in the following spring, it will be found that the inner bark has never become lengthened. The upper part of a branch and a flower-bud is formed only by the pirh, the medullary sheath, and the bark. I think I may conclude from this obscrvation, that the increase of the stems or trunks, and the ramifications, depends merely on the elongation of the vessels of the medullary sheath. The allurnum, the tubes of which have a direction perfectly. straight, presents itself at the upper part of a branch under the form of separate fibres, which lose themselves at the surface of the medullary sheath. This observation explains to us also why the zones of the upper part of a branch are in number inferior to those of the base. It confirms also what I have said in regard to the birth of buds; for, if we examine the bud of a small branch in any tree whatever, we shall be convinced that it is the mcdullary sheath without exception that composes alone the interior of that organ.

Explanation of the figures lelonging to the alove article. See Plate III.

Fig. 1, A vertical section of a piece of a branch of shumac.

A, The bark.

$\mathrm{B}$, Ligneous zone of one year.

C, The medullary sheath.

D, A bud. bud.

E, The swelled-up part of the bark at the base of the

F, Herbaccous prolongation of the medullary sheath which has traversed the wood and given birth to the bud.

G, The pith. 
Buds and ramifications of Plants.

E D

Fig. 5.
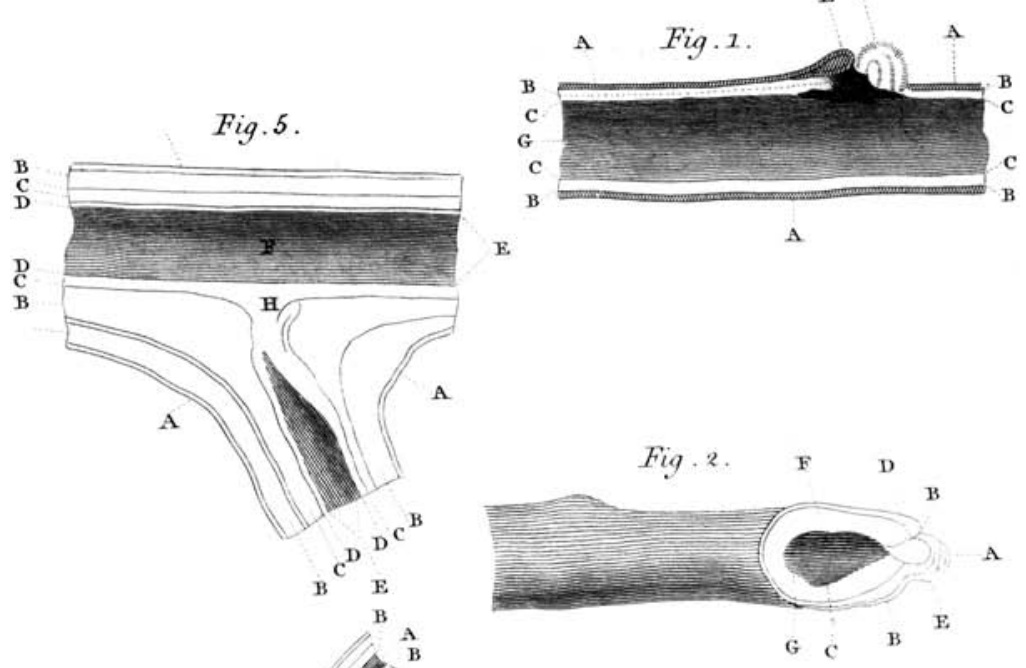

E

B A B

Fig. 7 .

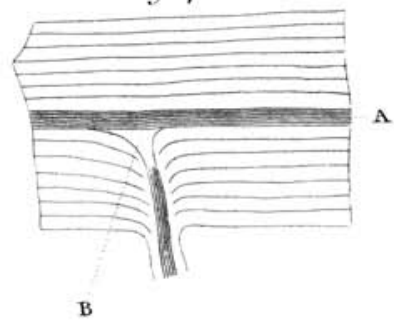

Fig. 4 .
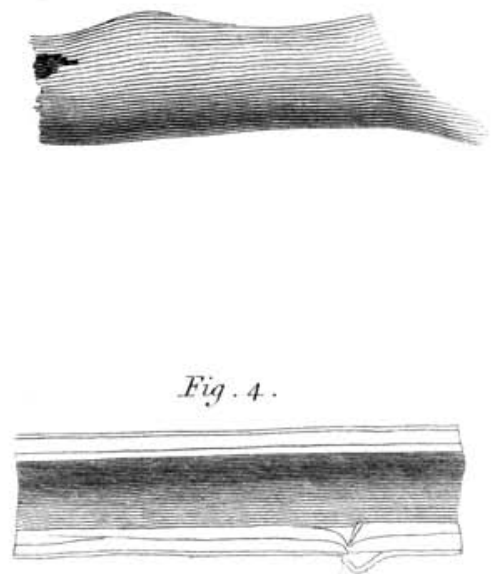

A 
Fig. 2, A similar, cut obliquely at the place where the prolongation passes through the wood.

A, A bud.

B, The bark.

C, Ligneous zone of the year.

$D$, Herbaceous prolongation of the medullary sheath passing through the wood and entering the bud.

$\mathrm{E}$, The swelled part of the bark at the sides of the bud.

F, The pith.

G, The medullary sheath.

Fig. 3, The same piece seen in profile, to show the angle of the section.

Fig. 4, Vertical section of a piece of shumac of two years old, bearing a bud.

$A$, The bud produced from an herbaceous prolongation of the medullary sheath, which prolongation has passed through the two ligneous strata.

Fig. 5, Vertical section of a branched piece of shumac.

A, The bark.

$B$, Ligneous stratum of the second year.

C, Ligneous stratum of the first year.

$D$, Stratum arising from the lignification of the exteriar part of the pith.

E, Medullary sheath of a branch.

F, Medullary sheath of a twig.

G, Pith.

H, Prolongation of the medullary sheath, become ligneous, and confounded with the wood produced by the pith.

Fig. 6, Vertical section of a branched piece of the plaanus occidentalis.

A, Pith.

B, Medullary sheaths.

C, Ligneous stratum of the first year.

$D$, Ligneous stratum of the second year.

$\mathbf{E}$, Lignified prolongations of the medullary sheath.

Fig. 7, Vertical section of a piece of hazle, bearing a twig with false wood, which has only one ligneous zone, and which has arisen from a prolongation of the medullary sheath, which prolongation, in order to produce the bud from which the twig resulted, has passed through sexen zones of wood, and at length become ligneous.

[To be concluded in our next.]

Vol. 22. No. 87. August i805. $\mathbb{Q} \quad$ XXXVI. Method 